\title{
Effect of maternal anemia on cord blood haemoglobin of newborn
}

\author{
Richa Rathoria ${ }^{1}$, Ekansh Rathoria ${ }^{2 *}$
}

\begin{abstract}
${ }^{1}$ Department of Obstetrics and Gynaecology, Hind Institute of Medical Sciences, Safedabad, Barabanki, UP, India
${ }^{2}$ Department of Pediatrics, Hind Institute of Medical Sciences, Safedabad, Barabanki, UP, India
\end{abstract}

Received: 15 December 2021

Accepted: 30 December 2021

\author{
*Correspondence: \\ Dr. Ekansh Rathoria, \\ E-mail: rathoriaekansh@yahoo.com
}

Copyright: () the author(s), publisher and licensee Medip Academy. This is an open-access article distributed under the terms of the Creative Commons Attribution Non-Commercial License, which permits unrestricted non-commercial use, distribution, and reproduction in any medium, provided the original work is properly cited.

\section{ABSTRACT}

Background: Anemia during pregnancy is linked to major maternal and fetal problems. The aim of the study was to find any correlation between maternal anemia and neonatal cord blood haemoglobin $(\mathrm{Hb})$ levels.

Methods: This cross-sectional study was done in the department of pediatrics and department of obstetrics and gynaecology at the Hind Institute of Medical Sciences, Barabanki over 9 months from January 2021 to September 2021. A total of 308 pregnant females more than 34 weeks of gestation who delivered participated in the study and cord blood hemoglobin of their new-born was collected. The mean maternal hemoglobin and mean cord blood hemoglobin were compared using the Pearson correlation coefficient in different groups i.e., non-anemic, anemic, mild, moderate, and severe anemic groups.

Results: Out of 308 pregnant women, 198 (64.3\%) were anemic, and 110 (35.7\%) were nonanemic. The mean maternal hemoglobin among non-anemic mothers and anemic mothers was $11.91(0.70)$ and 9.14 (1.56) respectively. The Pearson correlation coefficient of non-anemic, anemic, mild, moderate, and severe anemic groups were 0.6985, 0.8453, 0.7772, 0.6321 , and 0.7226 respectively with a statistically significant $p$ value $<0.05$ showing a positive correlation between maternal hemoglobin and cord hemoglobin.

Conclusions: From this study, we concluded that maternal anemia affects neonatal cord blood hemoglobin. According to the findings, anemic women deliver new-born with lower hemoglobin levels than non-anemic mothers. The findings revealed a linear correlation between maternal hemoglobin and cord blood hemoglobin of their new-born.

Keywords: Cord hemoglobin, Maternal anemia, New-born

\section{INTRODUCTION}

Anemia during pregnancy is very common in developing countries. According to data from the WHO/World Health Statistics, 40.1 percent of pregnant women worldwide were anemic in 2016. ${ }^{1}$ The problem is particularly prevalent in Southeast Asian countries, where anemia is responsible for about half of all maternal mortality worldwide, with India accounting for nearly $80 \%$ of all maternal deaths in South Asia ${ }^{1}$.

In India, the prevalence of anemia in pregnant women aged 15-49 years has decreased somewhat from 57.9 percent in the NFHS-3 (National Family Health Survey-2005-06) to
50.4 percent in the NFHS-4 survey $(2015-16)$ but in NFHS-5 (2019-21) it has increased to 52.2 percent. $^{2-4}$

Maternal anemia during pregnancy is defined as a $\mathrm{Hb}$ level of less than $11 \mathrm{~g} / \mathrm{dl}$, according to the WHO. Mild, moderate, and severe anemia in pregnancy is defined by Haemoglobin $(\mathrm{Hb})$ values of 10 to $10.9 \mathrm{~g} / \mathrm{dl}, 7$ to $9.9 \mathrm{~g} / \mathrm{dl}$, and less than $7 \mathrm{~g} / \mathrm{dl}$, respectively. ${ }^{5}$ Maternal anemia has several negative consequences for both the mother and the fetus' health. Iron deficiency is the most prevalent cause of maternal anemia either due to reduced iron availability or increased iron demand by a developing foetus. ${ }^{6}$ Although, it can also be caused by dietary deficiencies (folic acid and vitamins A, B, and C), infections like 
malaria or helminthiasis, or chronic diseases like TB or HIV. ${ }^{6}$ Previous studies have found a link between maternal anemia and negative pregnancy outcomes such as Low birth weight (LBW), preterm birth, Small-forgestational-age (SGA), postpartum hemorrhage, and eclampsia. $^{7}$

The umbilical cord blood $\mathrm{Hb}$ is an essential predictor of anemia in newborns at delivery. ${ }^{8}$ It was formerly assumed that regardless of the mother's Hb level, the baby would not be anemic. According to several research, women who had iron deficiency anemia during pregnancy gave birth to babies with decreased $\mathrm{Hb}$ levels in their cord blood. ${ }^{9}$ Recent research has discovered a linear correlation between mother $\mathrm{Hb}$ and cord blood $\mathrm{Hb}$ of newborns. ${ }^{10}$ Umbilical cord blood for newborn laboratory testing is a promising new method that has been found to enhance neonatal outcomes. ${ }^{11}$ As a result, full implementation of this method is a critical step toward improved usage of umbilical cord blood in improving neonatal outcomes.

More research is required to validate the significant correlation between maternal $\mathrm{Hb}$ levels and neonatal cord blood $\mathrm{Hb}$ levels. The aim of the study was to see how maternal anemia affected newborn cord blood $\mathrm{Hb}$.

\section{METHODS}

This cross-sectional study was done in the department of pediatrics and department of obstetrics and gynaecology at the Hind Institute of Medical Sciences, Safedabad, Barabanki over 9 months from January 2021 to September 2021. All pregnant women more than 34 weeks of gestation and their new-borns were included in the study. We excluded those mothers who had risk factors like antepartum haemorrhage, gestational diabetes mellitus, pregnancy-induced hypertension, renal diseases, hypothyroidism, and those newborns with twin deliveries, birth asphyxia, congenital anomalies, and pathological jaundice e.g., Rh incompatibility. A total of 308 pregnant females participated in the study and the cord blood $\mathrm{Hb}$ of their new-borns was collected after obtaining informed consent from them. Maternal $\mathrm{Hb}$ was tested before delivery and mothers were divided into two groups based on maternal $\mathrm{Hb}$ levels: non-anemic $(\mathrm{Hb} \geq 11 \mathrm{~g} / \mathrm{dl})$ and anemic group $(\mathrm{Hb}<11 \mathrm{~g} / \mathrm{dl})$. The anemic group was further divided into mild ( $\mathrm{Hb} 10-10.9 \mathrm{~g} / \mathrm{dl})$, moderate (7-9.9 g/dl), and severe anemia groups $(\mathrm{Hb}<7 \mathrm{~g} / \mathrm{dl})$. The conventional spectrophotometric cyanmet $\mathrm{Hb}$ methodology was used to quantify the $\mathrm{Hb}$ concentration.

The sample size was calculated to be 264 with a confidence interval of $95 \%$ and a margin of error of $5 \%$ by using the formula:

$$
\frac{4 P Q}{L^{2}}
$$

taking 78 percent prevalence of anemia at the time of delivery in antenatal mothers from a recent study from Northern India. ${ }^{12}$ The actual study was done on 308 mothers. Data were analyzed in descriptive statistics using SPSS software version 26. The Pearson correlation coefficient was used to find a linear correlation between maternal anemia and cord blood $\mathrm{Hb}$ with a $\mathrm{p}$ value of less than 0.05 was considered statistically significant.

\section{RESULTS}

In the present study, 308 pregnant females were enrolled. Table 1 depicts the demographic profile of subjects. Out of 308 pregnant women, $198(64.3 \%)$ were anemic, and 110 $(35.7 \%)$ were nonanemic. The mean age [standard deviation (SD)] of non-anemic women and anemic women were 26.44 (4.78), and 25.96 (4.47) respectively. Among the 198 anemic mothers, $89(44.94 \%)$ had mild anaemia (Hb level:10-10.9 g/dl), 84 (42.42\%) had moderate anaemia $(9.9-7 \mathrm{~g} / \mathrm{dl})$ and $25(12.62 \%)$ had severe $(<7 \mathrm{~g} / \mathrm{dl})$ anaemia (Figure 1).

The mean maternal $\mathrm{Hb}$ and mean cord blood $\mathrm{Hb}$ were compared among non-anemic groups using the Pearson correlation coefficient $(\mathrm{R}=0.6985)$ and found to be positively correlated with statistically significant with a $\mathrm{p}$ value of $<0.00001$. Similarly, the Pearson correlation coefficient of anemic, mild, moderate, and severe anemic groups were $0.8453,0.7772,0.6321$, and 0.7226 respectively with a statistically significant $\mathrm{p}$ value $<0.05$ showing a positive correlation between maternal $\mathrm{Hb}$ and cord $\mathrm{Hb}$ (Table 2).

Table 1: Demographic profile of subjects $(n=308)$.

\begin{tabular}{|c|c|c|c|}
\hline \multirow{2}{*}{\multicolumn{2}{|c|}{ Parameters }} & \multicolumn{2}{|c|}{ Number of subjects } \\
\hline & & $\mathbf{N}$ & $\%$ \\
\hline \multirow{3}{*}{ Age of mother (year) } & $<20$ & 21 & 6.8 \\
\hline & $20-30$ & 230 & 74.7 \\
\hline & $>30$ & 57 & 18.5 \\
\hline \multirow{2}{*}{ Livelihood } & Rural & 199 & 64.6 \\
\hline & Urban & 109 & 35.4 \\
\hline \multirow{3}{*}{ Education } & Illiterate & 25 & 8.1 \\
\hline & Below high school & 96 & 31.2 \\
\hline & Above high school & 187 & 60.7 \\
\hline Socio-economic status & Low & 67 & 21.8 \\
\hline
\end{tabular}




\begin{tabular}{|c|c|c|c|}
\hline \multirow{2}{*}{ Parameters } & & \multicolumn{2}{|c|}{ Number of subjects } \\
\hline & & $\mathbf{N}$ & $\%$ \\
\hline \multirow{7}{*}{ Religion } & Middle & 212 & 68.8 \\
\hline & Upper & 29 & 9.4 \\
\hline & Hindu & 152 & 49.3 \\
\hline & Muslim & 108 & 35.1 \\
\hline & Sikh & 15 & 4.9 \\
\hline & Christian & 10 & 3.2 \\
\hline & Others & 23 & 7.5 \\
\hline \multirow{2}{*}{ Gestational age (weeks) } & $34-<37$ & 165 & 53.6 \\
\hline & $\geq 37$ & 143 & 46.4 \\
\hline Primigravida & & 139 & 45.1 \\
\hline Multigravida & & 169 & 54.9 \\
\hline \multirow{3}{*}{ Mode of delivery } & Vaginal & 189 & 61.4 \\
\hline & Caesarean section & 93 & 30.2 \\
\hline & Instrumental delivery & 26 & 8.4 \\
\hline \multirow{2}{*}{ Birth weight (g) } & $<2500$ & 185 & 60.1 \\
\hline & $\geq 2500$ & 123 & 39.9 \\
\hline \multirow{2}{*}{ Sex of new-born } & Male & 171 & 55.5 \\
\hline & Female & 137 & 44.5 \\
\hline
\end{tabular}

Note: *Number in parenthesis indicates the percentage.

Table 2: Correlation between maternal Haemoglobin $(\mathrm{Hb})(\mathrm{g} / \mathrm{dl})$ and cord $\mathrm{Hb}(\mathrm{g} / \mathrm{dl})$ among pregnant women $(\mathbf{N}=308)$.

\begin{tabular}{|llllll|}
$\begin{array}{l}\text { Pregnant women Hb in } \\
\text { g/dl }\end{array}$ & $\mathbf{N}$ & $\begin{array}{l}\text { Mean maternal Hb } \\
\text { in g/dl (SD) }\end{array}$ & $\begin{array}{l}\text { Mean cord Hb in } \\
\text { g/dl (SD) }\end{array}$ & $\begin{array}{l}\text { Pearson correlation } \\
\text { coefficient }(\mathbf{R})\end{array}$ & P value $^{* *}$ \\
\hline Non-anemic $(\mathbf{H b} \geq \mathbf{1 1})$ & 110 & $11.91(0.70)$ & $16.82(1.48)$ & 0.6985 & $<0.00001$ \\
\hline $\begin{array}{l}\text { Anemic }(\mathbf{H b}<\mathbf{1 1}) \\
\text { Mild anemic }(\mathbf{H b} \mathbf{1 0 - 1 0 . 9})\end{array}$ & 198 & $9.14(1.56)$ & $15.38(0.99)$ & 0.8453 & $<0.00001$ \\
\hline $\begin{array}{l}\text { Moderate anemic }(\mathbf{H b} 7- \\
\text { 9.9) }\end{array}$ & 84 & $\mathbf{1 0 . 4 5 ( 0 . 2 8 )}$ & $15.97(0.98)$ & 0.7772 & $<0.00001$ \\
\hline Severe anemic $(\mathbf{H b}<\mathbf{7})$ & 25 & $6.13(0.76)$ & $15.06(0.64)$ & 0.6321 & $<0.00001$ \\
\hline
\end{tabular}

Note: *Data presented as mean [Standard deviation (SD)]; **p value less than 0.05 being statistically significant.

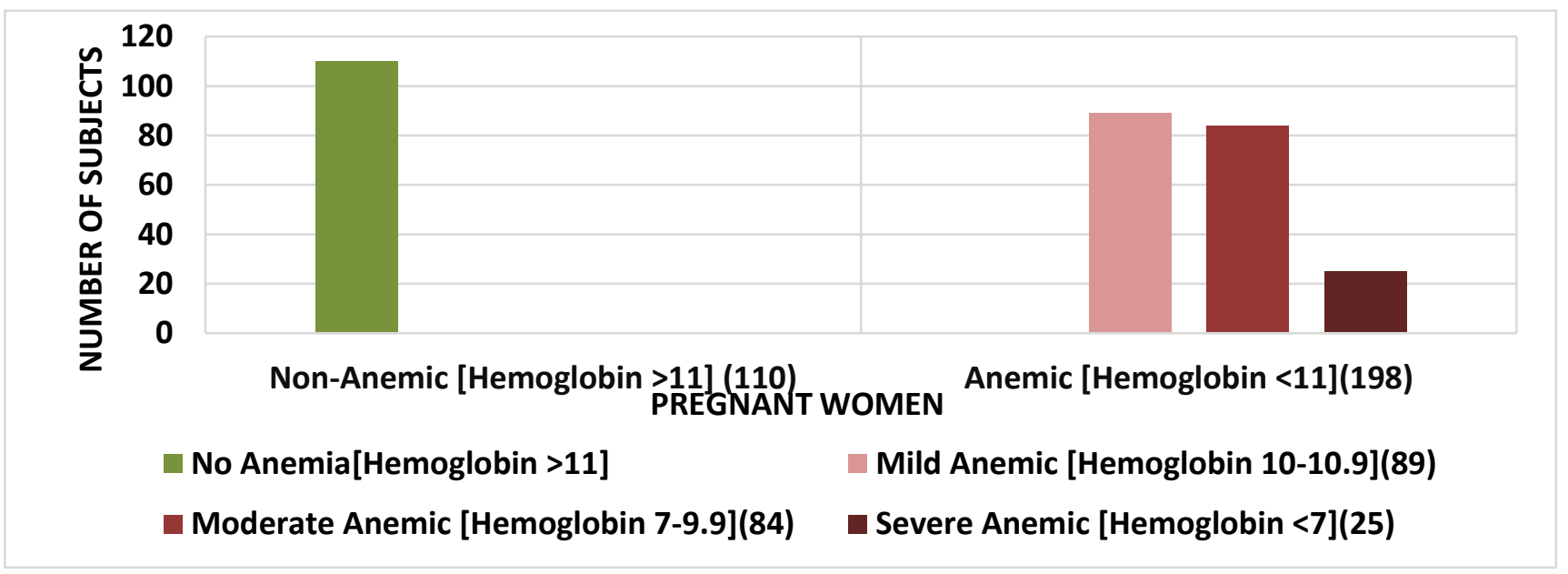

Figure 1: Distribution of pregnant mothers according to $\mathrm{Hb}$ values (g/dl) $(\mathrm{N}=308)$.

\section{DISCUSSION}

In the present study, $230(74.7 \%)$ pregnant women were between the age of 20-30 years, 199 (64.6\%) were from rural livelihood, $187(60.7 \%)$ were educated above high school standard, $212(68.8 \%)$ were from middle socioeconomic status, $152(49.3)$ were Hindus and 108 (35.1) were Muslims, 165 (53.6\%) were between 34-<37 weeks gestational age, $169(54.9 \%)$ were multigravida, $189(61.4 \%)$ delivered vaginally, $185(60.1 \%)$ delivered babies with birth weight $<2500 \mathrm{~g}$ and $171(55.5 \%)$ were males (Table 1). Our study findings matched those of 
Klebanoff et al (1991) and Lu et al (1991), who reported a relationship between maternal anemia and a higher risk of preterm delivery. ${ }^{13,14}$ The present study findings were similar to a study done by Prasad et al who reported a positive significant association with an increasing number of children and gravida status. ${ }^{15}$ Our findings were comparable to those of Tembhare et al who discovered that the number of vaginal deliveries, instrumental deliveries, and caesarean sections (LSCS) was similar in both anemic and non-anemic mothers, but that more anemic mothers required induction of labor. ${ }^{16}$ Our findings matched those of Figueiredo et al who found that maternal anemia was linked to low/insufficient birth weight, indicating that it was a risk factor for the gestational outcomes evaluated. ${ }^{17}$

The present study compared maternal $\mathrm{Hb}$ to neonatal cord $\mathrm{Hb}$ to see if there was any correlation between the two measurements. As the mean maternal $\mathrm{Hb}$ decreased, the mean cord $\mathrm{Hb}$ fell as well indicating a linear correlation between cord $\mathrm{Hb}$ and maternal $\mathrm{Hb}$ in our study. This indicates that maternal anemia affects cord $\mathrm{Hb}$. This shows that at higher levels of anemia, placental iron transport mechanisms may fail, resulting in a drop-in cord $\mathrm{Hb}$.

Findings from our study were similar to a study done by Timilsina et al which reported maternal and foetal $\mathrm{Hb}$ had a moderately positive correlation. ${ }^{18}$ Our findings were comparable to a study done by Sareen et al which concluded that neonates born to anemic mothers had lower cord blood $\mathrm{Hb}$ as compared to non-anemic mothers. ${ }^{19}$ Also, our findings were akin to a study conducted at Babylon University by Najeeba et al which found a linear relationship between maternal $\mathrm{Hb}$ and new-born cord haemoglobin. ${ }^{20}$ Debbarma et al found a linear association between the cord and maternal $\mathrm{Hb}$, which is similar to the current study. ${ }^{21}$ In another study done by Mamoury et al from North-eastern Iran reported contradictory findings that there is no association between cord blood $\mathrm{Hb}$ and maternal $\mathrm{Hb}^{22}$

\section{Limitations}

Limitations of the study were as follows: (a) the iron status of the mother was not determined; and (b) maternal $\mathrm{Hb}$ levels were not determined in the first and second trimesters.

More research could be done by correlating maternal $\mathrm{Hb}$ levels and iron status in the first, second, and third trimesters of pregnancy to low cord $\mathrm{Hb}$ levels in anemic mothers.

\section{CONCLUSION}

This study concluded that maternal anemia affected neonatal cord $\mathrm{Hb}$. According to the findings, anemic mothers deliver babies with lower $\mathrm{Hb}$ levels than nonanemic mothers. The findings reveal a linear correlation between maternal $\mathrm{Hb}$ and cord blood $\mathrm{Hb}$ of their newborns. Prophylaxis during pregnancy might prevent anemia in underdeveloped nations like India, perhaps lowering the risk of foetal and maternal problems thereby improving overall new-born survival rates.

\section{ACKNOWLEDGEMENTS}

The authors would like to thank all the junior residents of the Department of Pediatrics and mothers involved in the study.

\section{Funding: No funding sources \\ Conflict of interest: None declared \\ Ethical approval: The study was approved by the Institutional Ethics Committee}

\section{REFERENCES}

1. National Health Portal of India. Diseases/conditions information: Anaemia during pregnancy (Maternal anemia), 2021. Available at: https://www.nhp.gov.in/disease/gynaecologyandobst etrics/anaemia-during-prmaternalanemia. Accessed on 05 December 2021.

2. National Family Health Survey. NHFS 3 Publications Fact sheets India, 2021. Available at: http://rchiips.org/nfhs/pdf/India.pdf. Accessed on 05 December 2021.

3. National Family Health Survey. NHFS 4 Publications Fact sheets India, 2021. Available at http://rchiips.org/nfhs/pdf/NFHS4/India. Accessed on 05 December 2021.

4. National Family Health Survey. NHFS 5 Publications Fact sheets India, 2021. Available at: http://rchiips.org/nfhs/NFHS-5FCTS/India. Accessed on 05 December 2021.

5. WHO. Hemoglobin concentrations for the diagnosis of anemia and assessment of severity. Vitamin and Mineral Nutrition Information System, 2011. Available at: https://www.who.int/vmnis/indicators/haemoglobin.p df. Accessed on 05 December 2021.

6. Jung J, Rahman MM, Rahman MS, Swe KT, Islam MR, Rahman MO, et al. Effects of hemoglobin levels during pregnancy on adverse maternal and infant outcomes: a systematic review and meta-analysis. Ann N Y Acad Sci. 2019;1450(1):69-82.

7. Breymann C, Bian XM, Capito LR, Chong C, Mahmud G, Rehman R. Expert recommendations for the diagnosis and treatment of iron-deficiency anemia during pregnancy and the postpartum period in the Asia-Pacific region. J Perinat Med. 2011;39(2):11321.

8. Rajendran R, Suman FR, Sudheer Raj RS, Rajesh Kanna P, Borra NR. Umbilical Cord Blood Hemogram: What Is the Effect of Maternal Anemia?. Blood. 2015;126(3):4536.

9. Shukla AK, Srivastava S, Verma G. Effect of maternal anemia on the status of iron stores in infants: A cohort study. J Family Community Med. 2019;26(2):118-22. 
10. Bernhardt GV, Jhancy M, Shivappa P, Bernhardt K, Pinto JR. Relationship between Maternal and Cord Blood Iron Status in Women and their New Born Pairs. Biomedical and Pharmacol J. 2021;14(1):31723.

11. Kohli UA, Rajput M, Venkatesan S. Association of maternal hemoglobin and iron stores with neonatal hemoglobin and iron stores. Med J Armed Forces India. 2021;77(2):158-64.

12. Kant S, Kaur R, Goel AD, Malhotra S, Haldar P, Kumar R. Anemia at the time of delivery and its association with pregnancy outcomes: A study from a secondary care hospital in Haryana, India. Indian J Public Health. 2018;62(4):315-8.

13. Klebanoff MA, Shiono PH, Selby JV, Trachtenberg AI, Graubard BI. Anemia and spontaneous preterm birth. Am J Obstet Gynecol. 1991;164(1):59-63.

14. Klebanoff MA, Shiono PH, Selby JV, Trachtenberg AI, Graubard BI. Anemia and spontaneous preterm birth. Am J Obstet Gynecol. 1991;164(1):59-63.

15. Prasad SG. Relationship between gravida status and severity of anemia? Int J Med Sci Educ. 2019;6(4):814.

16. Tembhare A, Shelke S, Shivkumar PV, Tayade S. Iron deficiency anemia in pregnant mothers as a cause of poor maternal health in rural India. Endocrinology. 2015;3(2)128-37.
17. Figueiredo ACMG, Filho IS, Batista JET, Orrico GS, Porto ECL, Cruz PRM, et al. Maternal anemia and birth weight: A prospective cohort study. PLoS One. 2019;14(3):212817.

18. Timilsina S, Karki S, Gautam A, Bhusal P, Paudel G, Sharma D. Correlation between maternal and umbilical cord blood in pregnant women of Pokhara Valley: a cross sectional study. BMC Pregnancy Childbirth. 2018;18(1):70.

19. Sareen A, Singh S, Mahajan K. Maternal Anemia and its Effect on Cord Hemoglobin. Paediatr Rev Int J Paediatr Res. 2018;5(7):351-4.

20. Najeeba CM, Prabhu AS, Saldanha PR. Maternal anemia and its effect on cord blood hemoglobin and newborn birth weight. IOSR J Dent Med Sci. 2015;14(7):30-2.

21. Debbarma R, Debbarma B, Devi MA. Effect of maternal anaemia on cord haemoglobin and birth weight of newborns. IOSR J Med Sci. 2015;14(7):1921.

22. Mamoury GH, Hamedy AB, Akhlaghi F. Cord hemoglobin in newborns in correlation with maternal hemoglobin in northeastern Iran. Iranian J Med Sci. 2015;28(4):166-8.

Cite this article as: Rathoria R, Rathoria E. Effect of maternal anemia on cord blood haemoglobin of newborn. Int J Reprod Contracept Obstet Gynecol 2022;11:64-8. 